This is a post-print (author's final draft) of a chapter in the book by Irène

Deliège and Geraint Wiggins (Eds.) (2006). Musical Creativity:

Multidisciplinary Research in Theory and Practice (pp. 42-59). Oxford:

Psychology Press. Details of the book version are available at

http://books.google.be/books/about/Musical_Creativity.html?id=IBQgoWFfSOg

C\&redir_esc $=\mathrm{y}$

\title{
Musical creativity between symbolic modelling and perceptual constraints: the role of adaptive behaviour and epistemic autonomy.
}

\author{
Mark Reybrouck \\ University of Leuven
}

\begin{abstract}
[42] This paper addresses the topic of musical creativity and its underlying mechanisms. An operational definition is provided in an attempt to bring together in a theoretical framework such distinct musical behaviours as listening, performing and composing. Based on the concepts of adaptation and the epistemic control system, it is possible to conceive of the music user as an adaptive device responding to the sonic environment. In order to do so he or she can make new distinctions, perform internal computations on the observables and create different semantic relations with the sonic world. As such it is possible to go beyond perceptual constraints and to conceive of coping with music in terms of creative thinking and epistemic autonomy. A central thesis in this approach is that creativity occurs at the epistemic levels of musical input and output as well as at the computational level.
\end{abstract}

\section{Introduction}


This paper addresses the concept of musical creativity. Rather than giving an overview of established views on the subject, it aims to introduce a theoretical framework which should provide an operational description of creativity by approaching it from the positions of cybernetics and systems theory (see Reybrouck 2004a). As such it should go beyond those approaches which conceive of the process of creativity only at the level of composing and performance, and which focus mainly on a rather limited range of music. The approach I propose locates musical creativity both at the level of the reception and performance of music, and at the level of internal processing. As such it allows us to conceive of musical creativity in interactional terms as "coping with the sonic world".

In order to do this I argue for the introduction of an operational terminology which describes the basic functions of dealing with music and which has explanatory power as well. Basic to this approach are the conception of musical creativity as an adaptive process of "knowledge acquisition", and the possibility of carrying out "symbolic operations" on the acquired elements.

Several questions should be raised here:

(1) How do we deal with music? Is it something "out there", allowing us to conceive of music in "objectivist" terms without any reference to the music user, or does it call forth interactions with the sound, stressing the role of the music user as well?

(2) What kinds of interactions are at work in dealing with music? Do we interact with "actual" sounding material, immediately present as in listening and performing, or do we deal with music at an internalised, virtual level, relying on memory and imagery?

(3) What is the mechanism of sense-making in dealing with music? Do we rely on continuous processing of acoustic information - as a kind of servomechanism - or can we keep distance with respect to the perceptual flux and deal with music in a kind of symbolic play?

(4) And (4) what is the role of creativity in this process of dealing with music?

[43] These questions are related to the pragmatic claims of Dewey, who characterized experience as an interplay between doing and undergoing: 
"In short, art, in its form, unites the very same relation of doing and undergoing, outgoing and incoming energy, that makes an experience to be an experience ... The doing or making is artistic when the perceived result is of such a nature that its qualities as perceived have controlled the question of production. ... The artist embodies in himself the attitude of the perceiver while he works." (1958[1934], p. 48)

\section{The epistemic control system as a starting point}

Dealing with music is a process that goes beyond the particularities of musical behaviours such as listening, composing or performing. It is a general term that allows us to conceive of music in terms of coping with the sonic world (Reybrouck 2001a, 2004a), and to conceive of music users as devices interacting with the external world. Such devices function as informationally open systems with sensory inputs, motor outputs and co-ordinations between them to form simple "perception-cognition-action loops" (Cariani 1989). As such they are related to the epistemic control system which draws a distinction between input, output, central processing and feedback (figure 1).

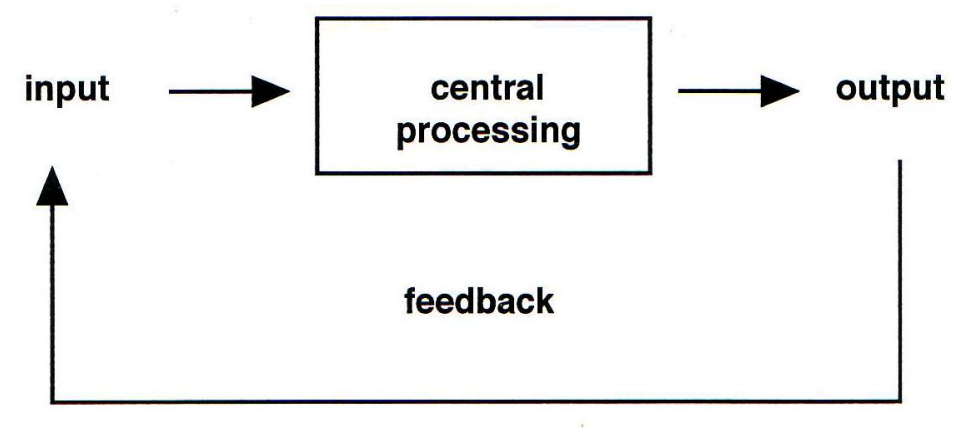

Figure 1. The basic schema of a control system

The epistemic control system is an old and much used concept which embraces the major moments of cybernetic functioning. It allows us to conceive of the music user as 
an adaptive device going beyond the linear stimulus-reaction chain, and instead generating a cycle that functions as a closed loop. As such it invokes the concept of circularity, feeding the output back to the input, and allowing the music user to evaluate and control his/her output through the flexible coordination of perception and action.

The basic idea behind this concept is conservative behaviour, with the "servomechanism" as a prototypical example (Paillard 1994, Berthoz 1996). This means that the music user is in continuous interaction with his or her environment in an attempt to keep any disturbances within critical limits. Such conservative behaviour is obvious in many musical applications: to mention only four of them, the traditional pedagogy of [44] instrumental teaching involving a teacher/apprentice relationship, where the apprentice tries to imitate the teacher's playing; the act of playing music from a score; the act of improvising; and the act of composing.

Common to these "musical behaviours" is the process of sensory-motor integration, with a gradual shift from presentational immediacy (acoustic information is presented to the senses) to symbolic representation (there is no sensory input). Playing a musical instrument is a typical example of motor output, which becomes a behavioural response to perceptual input as soon as there is a modification or adjustment of the sound production as a result of feedback through the senses. What is at issue here is the possibility of comparing actual sounds with a kind of target performance which is either actually present (as in imitation), or present in imagery (as in aural training and silent reading). The same holds true for the act of improvising, in which the sounding result is constrained by some kind of schematic representation in the music user's mind. The whole process yields a sounding product-unlike in the case of composing, where the actual performance can be totally disconnected from the conception in the composer's mind. At an "ideational" level, however, there is still an input-output mapping, be it at the virtual level of mental simulation.

This distinction is important. It revolves around the construction of an internal model, which allows the music user to go beyond the constraints of perceptual bonding and to carry out mental operations on virtual elements. The presence or absence of sensory input or output is the critical factor here, involving a transition from sensory-motor co- 
ordination to simulation, with the latter relying on representation rather than on sounding material. The brain, then, no longer operates as a "controller" reacting to sensory stimulation, but as a "simulator" that carries out internal operations on mental replicas of the sound (Paillard 1994, 1990, Berthoz 1996, 1997). As such we can conceive of music users as devices with an internal model of the environment (Klaus 1972, Berthoz 1997). This is an interesting claim which has been developed in the domains of cybernetics, robotics (Ziemke \& Sharkey 2001, Cariani 1989, 1998a, b) and biosemiotics (von Uexküll 1957[1934], Meystel 1998, Emmeche 2001), and which stresses the role of the central processing of the control system: it allows us to deal with music in terms of internal simulation and symbolic play, which is, in fact, a game theoretical approach.

The game theoretical approach echoes the older concept of an epistemic rule system (Klaus 1972), w[45ith the epistemic generalisations of "homo sapiens", "homo faber" and "homo ludens" and their translation in terms of automata. As such we can substitute a "perception machine" for homo sapiens, an "effector machine" for homo faber and a "playing automaton" for homo ludens (figure 2). Each of these automata, moreover, can be considered as effecting a specific function, which can be modified up to a certain degree, allowing us to conceive of the music user as an adaptive device. 


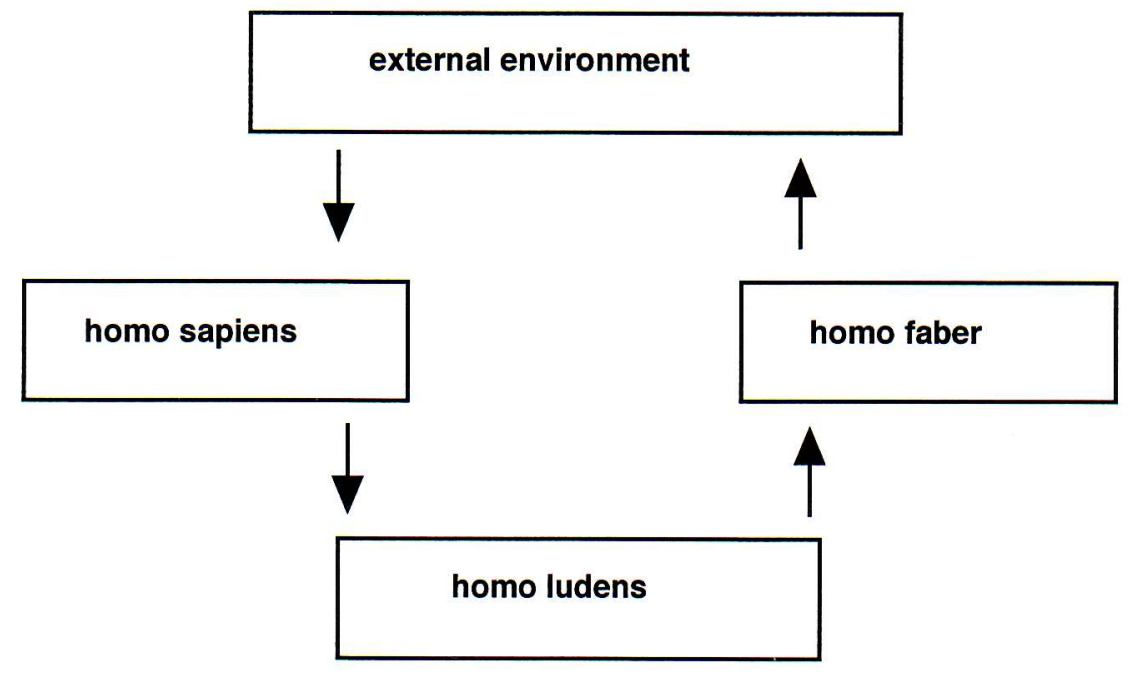

Figure 2. The epistemic rule system (after Klaus 1972)

\section{The music user as an adaptive device}

Dealing with music is a process of coping with the sonic world, whether at the level of actual sounding or at the level of imagery. It entails a constructive process of sensemaking that matches the perceptual input against a knowledge base and co-ordinates it with possible behavioural responses. This is the standard theory of cybernetic functioning, which can be easily translated to the realm of music. The music user, on this view, can be considered as a device made up of sensors, co-ordinative computations (input/output mappings) and effectors, somewhat analogous to the primitive functions of measurement, computation and control (Cariani 1989, see figure 3a). These functions can be considered in terms of their organismic counterparts, such as perceptions, actions and flexible perception-action co-ordinations, and each of them can be a locus for adaptation. Contemporary conceptions of learning devices have focussed mostly on the coordinative, cognitive adaptation located in the computational part of the rule system, allowing us to conceive of the music user as a "formal-computational device". 
The idea is appealing and is not uncommon in post-war music theory, which deals mostly with sets of elements which can be handled in a symbolic way (a representative example is Forte 1973). It is possible, however, to broaden the computational approach and to consider the functions of perception and action as well. But before doing this I will first elaborate on the concepts of computation and artificial devices in an attempt to apply them to the realm of music.

Computations are considered mainly from a symbol-processing point of view. The basic idea behind this approach is formal symbol manipulation by axiomatic rules, with a complete conceptual separation between the symbols and their physical embodiment. It finds an implementation in computer programs which handle "discrete symbols" and "discrete steps" by rewriting them to and from memory to a sequence of rules (Pattee [46] 1995). There is, however, a broader conception of computation, which considers the input/output couplings which can be handled in terms of "modelling" or "predictive computations" (Bel \& Vecchione, 1993) and which entails the basic idea of the "homo ludens" as a playing automaton. Computation, on this broader view, embraces the whole field of mental operations which can be performed on symbolic representations of the sound.

Artificial devices are formal-computational devices, to the extent that they have no potential for adaptation in relation to perception and action. As such, they are limited in their semantic relations with the (sonic) world as they rely on a restricted and fixed set of elements and operations. It is possible, however, to conceive of "adaptive devices"devices that can adapt themselves through epistemic transactions with the external world.

This is a critical distinction, because it allows us to conceive of different kinds of artificial devices. According to Cariani there are basically three of them (figure 3).

(i) A formal-computational or nonadaptive device operates completely within the symbolic realm and is completely independent of its environment; it does not alter its structure on the basis of its experience and can be described only in 
terms of computations, lacking all kinds of real world (external) semantics (figure 3a).

(ii) An adaptive computational device alters the input-output algorithm of its computational part on the basis of its performance, but is constrained by the fixed, nonadaptive nature of its sensors and effectors (figure $3 \mathrm{~b}$ ).

(iii) Structurally adaptive devices construct new material structures and can evolve new semantic categories through the adaptive construction of sensors and effectors (figure 3c) (Cariani 1991).

The concept of an adaptive device is very fruitful. It has descriptive and explanatory power and can be applied very easily to music users, who can learn to make new distinctions--expanding their set of observables-- and to carry out new computations on them. Let us, for example, consider a composer who takes advantage of stereotyped combinations to generate music of an essentially non-creative nature--somewhat similar to the musical dice games popular in the eighteenth century (Kirnberger, Mozart, etc.). What he or she is doing is carrying out mental operations on a set of discrete elements. There is a set of pitches, ranging over seven octaves, a limited set of durations, a finite set of instruments, some dynamic indications and some rules of voice leading and harmony. The composer can listen to or perform the music, but this does not alter the elements and the rules of combination. There is a fixed lexicon (the elements) and a set of syntactic rules which are not altered by the act of composing. Such a composer can be considered as a formal-computational device.

The situation is different, however, if the composer is trying out new elements and combinations through exploratory listening and performing, allowing him or her to [48] change the syntax and semantics. In this way the sound experiments of Debussy, Ravel, Messiaen and Stockhausen are distinct from stereotyped combinatorialism: they are exploring new sounds or combinations of sounds and new rules of combination, and as such we can conceive of them as adaptive computational devices. The situation, however, becomes more complicated as soon as robots and computers replace the human ear and motor interfaces. Computers are able to make distinctions which go beyond the constraints of perception, and the same holds true for their performance 
abilities. We now have at our disposal tools for new kinds and more objective forms of listening (spectrographic listening, navigation tools for sonic browsing, see Aigrain 1999), for computer-aided composition and for performing. As such we can conceive of structurally adaptiv devices which are able to modify their sensors and effectors and which are implemented in computer technology.

The situation is different, however, if the composer is trying out new elements and combinations through exploratory listening and performing, allowing him or her to [48] change the syntax and semantics. In this way the sound experiments of Debussy, Ravel, Messiaen and Stockhausen are distinct from stereotyped combinatorialism: they are exploring new sounds or combinations of sounds and new rules of combination, and as such we can conceive of them as adaptive computational devices. The situation, however, becomes more complicated as soon as robots and computers replace the human ear and motor interfaces.

[48] 


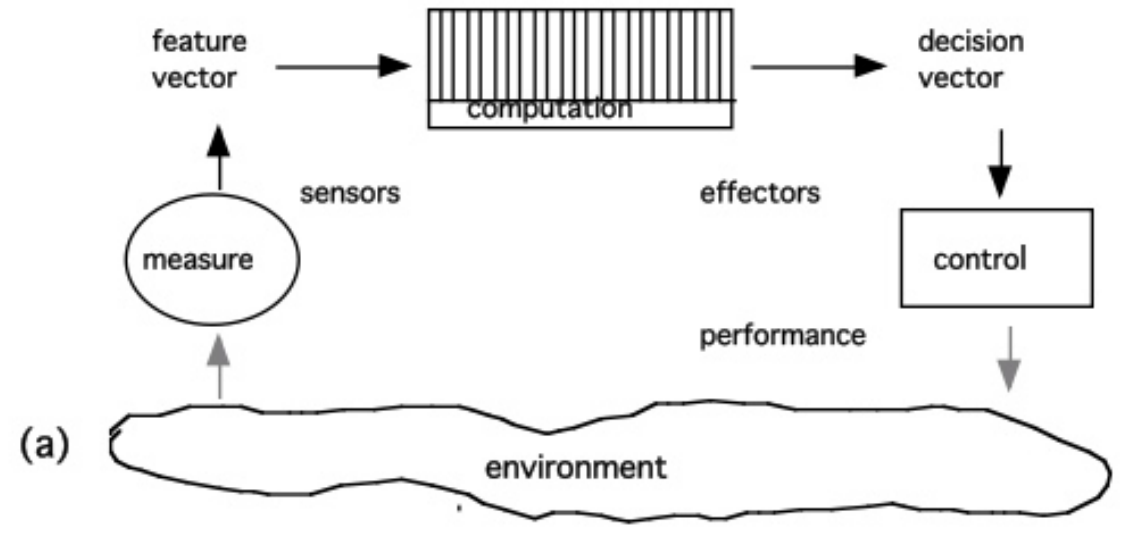

(b)

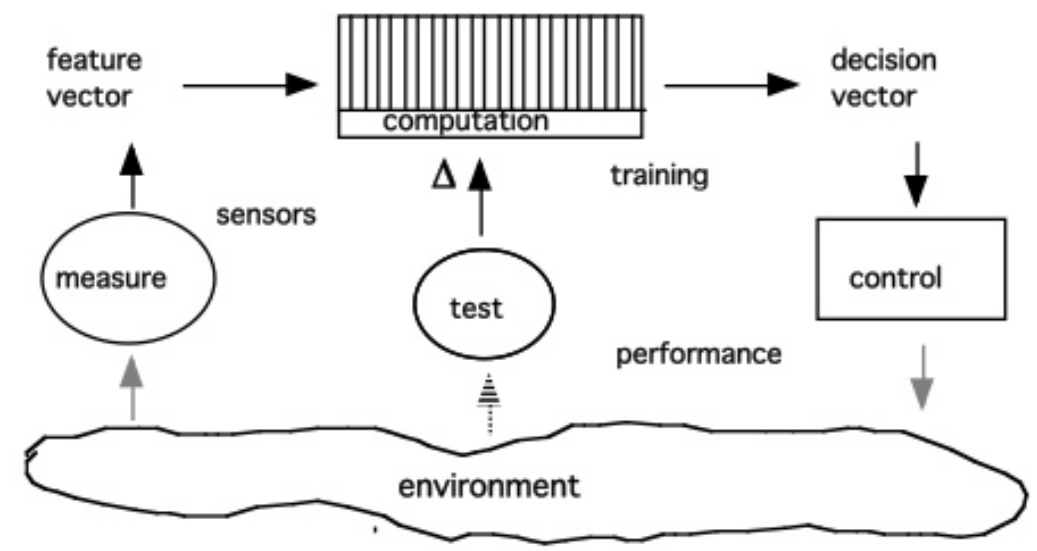

(c)

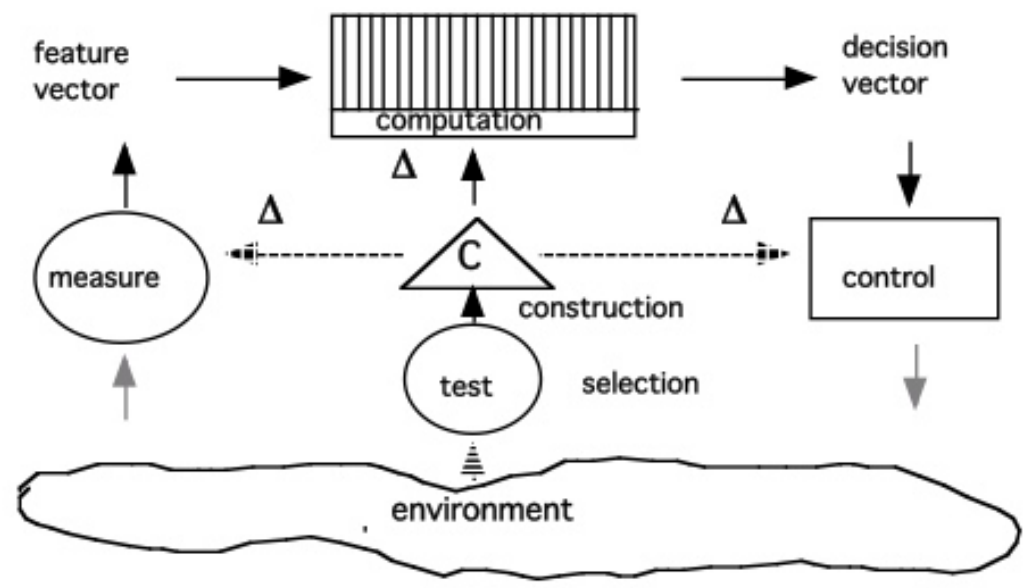

Figure 3. Three different kinds of artificial devices: (a) a formalcomputational or nonadaptive device is able to perform input-output coordinations and computations without altering its structure, (b) an adaptive computational device can alter its computational part, and (c) a 
structurally adaptive device can alter its sensors and effectors (after Cariani 1989, 1991 with permission).

Computers are able to make distinctions which go beyond the constraints of perception, and the same holds true for their performance abilities. We now have at our disposal tools for new kinds and more objective forms of listening (spectrographic listening, navigation tools for sonic browsing, see Aigrain 1999), for computer-aided composition and for performing. As such we can conceive of structurally adaptive devices which are able to modify their sensors and effectors and which are implemented in computer technology.

These claims are challenging. They raise the issue of epistemic autonomy, in that devices can arbitrarily choose what kinds of distinctions are to be made (perceptual categories, features and primitives), what kinds of actions are performed on the environment (primitive action categories), and what kinds of co-ordinative mappings are carried out between the two sets. To quote Cariani:

“... adaptive systems [...] continually modify their internal structure in response to experience. To the extent that an adaptive epistemic system constructs itself and determines the nature of its own informational transactions with its environs, that system achieves a degree of epistemic autonomy relative to its surrounds" (2001b, p. $60)$.

The musical applications of this approach are numerous. They are exemplified in the distinctions made by composers of the 20th century in their search for new sounds and timbres (Russolo, Varèse and many others). Influences such as "musique concrète" and electronic and electroacoustic music have renewed and challenged the basic principles of western music through stressing the role of sonority and timbre. And the role of the computer as an aid in composition has amplified the possibilities of making new distinctions and even manipulations of sound as well. There is a new science today which embraces the technology of both production and control of sound. Music theory, conceived in this light, relies on sensors instead of receptors, substituting tools for 
organs and introducing several kinds of machinery which can generate, transform and control many kinds of movements and sound production (Dufourt 2001). Musical instruments, too, have been transformed into automata which receive, transduce and analyse information.

But the concept of adaptive devices also applies to our dealings with music of the "common practice" tradition. As an example, consider the experience of a nineteenthcentury Adagio. What the listener hears is in essence a succession of sounds and sound configurations located in a time series and apparently selected from a virtual infinity of [49] possibilities. Very often the listener does not know in advance where the sound events are going to: this is a kind of listening "in suspense" that is typical of Romantic with its many modulations, digressions and developments. It cannot be stressed sufficiently that this music must be listened to in order to make sense, and this basically applies to all music. The multiple revisions of the symphonic music of Bruckner and Mahler illustrate the role of feedback through listening in shaping the final work. But it should be noted also that the vast majority of composers have always worked empirically at their instruments or at least alternating between instruments and desk. Eighteenth-century (and earlier) composers were without exception performers, and usually notable improvisers as well. It is only in the nineteenth and twentieth century that we begin to have composers who weren't performers.

All these claims have consequences for the process of dealing with music. There is, in fact, a tension between, on the one hand, modelling and simulation - which take place at a virtual level of dealing with the music - and on the other the actual experience of music as it sounds. The former can proceed autonomously and out-of-time, whereas the latter proceeds in real time and is constrained, because there are limitations as to what the listeners can distinguish. As such there can be a mismatch between what composers believe to be meaningful and what listeners actually hear and process. The same holds true for computer-aided composition, which has the potential to transcend traditional limits of perception and performance. The crux of the matter, however, is the possibility of changing relations with the external world: it is this that allows us to conceive of the music user as an "adaptive device" capable of changing its sensors, effectors and computations. 


\section{Adaptive behaviour and the concept of creativity}

Adaptation is a process that changes an organism in order for it to survive in its environment (Fleagle 1999). It is a biological concept which can be translated to the realm of cognition, as stressed by Piaget (1967). It has proven to be fruitful for educational theory and pedagogical practice in general, but can also be applied to music theory (Hargreaves 1986, Imberty 1996, Papousek 1996, Reybrouck 2001a). Central to this approach is the concept of equilibration as a mechanism that enables the organism to achieve a state of equilibrium, both within its cognitive structures and between these structures and the environment. These structures are seen as "unstable" in relation to new objects and experiences, and the tendency to equilibrate towards more stable states is a kind of intrinsic "cognitive drive" that motivates exploration (Hargreaves 1986, p. 33). As such, the environment provides a constant source of feedback, which guides the tendency to explore and to reach levels of stabilisation as the result of adaptation by the processes of assimilation and accommodation (figure 4).

The main idea is quite simple and is exemplified in figure 4. Equating the left side of the figure with the elements of the music, and the right side with the cognitive representations which can be applied to them, we can consider several mappings between them. If there is a perfect matching (one-to-one relationship) we can conceive of this as assimilation (figure 4a): the music user has the representations already installed in his/her mind. If, however, there are more elements in the music than there are representations in the music user's mind (figure 4b), there is a matching problem which must be solved by a process of accommodation: the music user must create new representations (figure 4c), but once these are installed, there is a perfect matching again. The music user, then, has adapted himself/herself and has achieved a new state of equilibrium. 
(a)

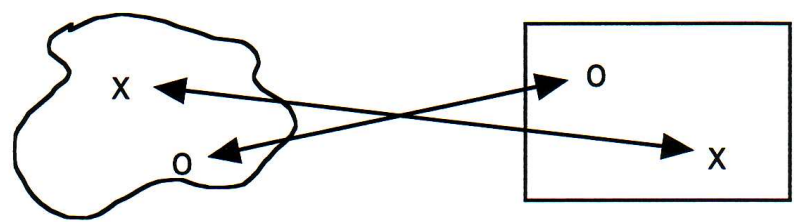

(b)

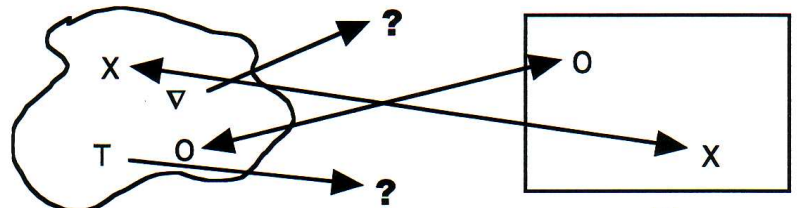

(c)

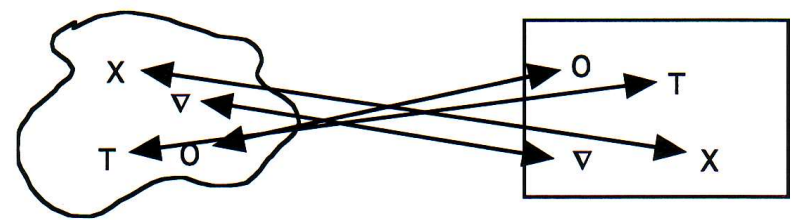

Figure 4. Assimilation and accommodation. The figure shows a matching between the elements of the music (left) and the cognitive representation in the mind (right). If there are as many elements in the music as in the mind (top), there is assimilation. If there are more elements in the music than in the mind (middle) the music user must accommodate, in order to provide a new matching and to achieve a new state of equilibrium (bottom).

There are many musical illustrations of these claims. Consider for example the music of the modernist tradition, which was at times problematic for the audience of the time. The classical example is Schoenberg whose serialism illustrates the non-co-ordination between "experienced" and "conceived structure", or put in other terms: between "composing" and "listening grammars" (see Lerdahl 1988). Many other examples could [51] be given which all illustrate the tension between music as an intelligible structure and the listener's capacities for making sense of it. Listeners, as a rule, should be able to co-ordinate the structure of the music with their cognitive structures. If this is not 
possible, there is a matching problem, which may invite them to accommodate in order to provide a new kind of mapping.

The Piagetian concept of equilibration is very useful here. It has profoundly influenced the constructivist approach to knowledge acquisition in general (von Glasersfeld 1995, Gardner 1991) and is likely to be of interest for the process of dealing with music as well. The roots of this approach can be traced back to Piaget and Dewey and place emphasis on creativity and motivation for learning through activity. Basic to this conception is the idea that knowledge must be constructed through interaction with the environment: this stresses the role of the subject who is doing the cognising, rather than conceiving of objects of cognition which are "out there". As such it is closely related to the "non-objectivist" and "enactive" approach to cognition (Lakoff 1987, Johnson 1987, and for a musical analogy, Reybrouck 2001a, b).

The idea of knowledge construction is very attractive. It allows us to conceive of musical creativity not only in computational terms but also in terms of "knowledge acquisition". It locates creativity also at the epistemic levels of musical input and output, somewhat concealing the interface between these levels. Musical input is classically seen as the subjection of acquired knowledge and perceptions to computation and modelling. Musical output--and here is the essential point--is not merely dependent on the computational process, but is closely involved in it, so that computation passes over from the adaptive processing of music into the production of new music.

We should take these claims seriously. They allow us to conceive of the music user as a learning and adaptive device coping with the sonic world: in doing so he or she can make new distinctions between the observables (perceptual primitives), carry out internal computations on them, and even act on them. This allows us, for short, to modify our semantic relations with the sonic world. According to Cariani (1991, 1998a, 2001a) there are three basic mechanisms for doing this: it is possible (i) to amplify the possibilities of participatory observation by expanding our perceptual and behavioural repertoire, (ii) to adaptively construct sensory and effector tools, and (iii) to change our cognitive tools as well. 
The musical analogies are obvious. As to the first, we should stress the importance of listening to a wide range of musics. This can be helpful for the creative music user to gain familiarity with measurable parameters such as pitch, timbre, duration and intensity and to broaden his/her perceptual categories. Different music cultures rely on different tone scales and divisions of the pitch continuum, and the same holds true for metrical-rhythmical groupings and divisions of time. But most striking is the richness of instrumental sounds which provide an infinite variety of possible distinctions within the [52] sonic world. In addition, there are highly interesting contributions from the search for new colours and the modifications and modulations of sound which are so typical of the past century's music. There is a whole body of work in which composers have focussed on the synthesis and elaboration of sound material (amplitudinal variation of attack, sustain and decay, variation of density, control of elementary parameters and frequency-energy relationships of the spectral components) (see Deliège 2001, Dufourt 2001): composers such as Messiaen, Boulez, Stockhausen, Ligeti, Xenakis, Berio, Nono and Carter illustrate the point, but we can conceive of contemporary music in general as a laboratory both for exploring the possibilities of natural sounding events and for the conception and realisation of new, non-natural sounds. It is up to the music user, then, to decide which distinctions will be made and to enhance the grip on the observables by choosing, selecting and delimiting some of them and raising them to the status of things which can be denoted deliberately (see also Reybrouck 1999, 2003, 2004b). As such the music user can expand his/her perceptual repertoire.

As to the second, we should conceive of the music user as an adaptive device able to modify or augment its "sensors" and to perform "active measurements" as a process of acting on the world and sensing how the world behaves as a result of these actions. The modification of its sensors allows the device to choose its own perceptual categories and control the types of empirical information it can access. Several strategies are available for doing this, but the basic mechanisms are reducible to two processes: altering existing sensing functions and adding new ones. This can be illustrated by means of technological tools for musical signal analysis and sound processing, but the modification of the effectors is equally important here, and is best illustrated through the evolution of musical instruments that go beyond a one-to-one mapping between the movements of the performer and the sounding result. This causal relationship is 
abandoned in computer music performance and the new generation of "logical" acoustic instruments, where controllers based on different kinds of sensors take over the continuous control of sound characteristics. The mapping, then, becomes a creative tool of performance and composition.

It is possible, finally, to change the cognitive tools as well, with or without modifying the sensory or effector tools. Here the role of cognitive mediation comes in, allowing the music user to perform symbolic operations on the mental replicas of the sound (Reybrouck 2004b). It is this that most closely approximates to the common view of musical creativity.

\section{The concept of creativity: from intuitive to operational approach}

The concept of creativity is a very topical issue in music theory. It is related to creative production, problem solving and divergent thinking in general, but it is quite difficult to put it in an operational format. Many definitions are intuitive rather than formal and [53] operational, and most of them deal almost exclusively with the computational level of the control system. A typical example is the distinction which the old Sanskrit scholars drew between the four stages in the articulation of thought: at first there is an empty space with undefined elements of thoughts, then comes the grasping of the thoughts at a preverbal level, followed by the formulation of words at a mental level, with as a final stage the explication of thought through articulate sounds (Daniélou 1967).

This intuitive approach has been remoulded several times. An example is the famous distinction which Wallas (1945[1926], see Webster 1990, 1992 for a musical analogy) drew between the four steps of creative thinking or production: preparation (information is gathered), incubation (work proceeds unconsciously and information is allowed to simmer or ripen), illumination ("inspired" solutions emerge), and verification (solutions are tested and elaborated). An analogous but more detailed description was proposed by Rossman (1931), who studied more than 700 reputable inventors and distinguished seven steps: a need or difficulty is observed, a problem is formulated, 
the available information is surveyed, a solution is formulated, the solutions are critically examined, new ideas are formulated, and the new ideas are tested and accepted.

These findings are interesting. They illustrate the connections between elements of creative thinking and problem solving already suggested by Dewey (1933), who distinguished five steps in problem solving: a difficulty is felt, the difficulty is located and then defined, possible solutions are suggested, consequences of these solutions are considered, and a solution is accepted, others having been rejected. The idea of "problem solving" has also been extensively elaborated by Guilford, who related it to "adaptive behaviour":

"It is recognized that there is a problem-solving activity whenever an individual encounters a situation for which he has no adequate response ready to function among his repertoire of reactions. If he tries at all to cope with the situation, he must adapt or modify his known responses or he must invent new ones." $\quad(1979, \mathrm{p} .113)$

The connection with creative thinking is obvious, but the same holds true for "divergent thinking" or "divergent production", which (according to Guilford's "Structure of Intellect Model") reads formally as:

"generation of information from given information, where the emphasis is upon variety and quantity of output from the same source; likely to involve transfer. " (Guilford 1967, p.213)

In order to be "productive", however, we need productive skills which allow us to formulate a problem and to solve it. In order to do so we rely on "divergent production"-abilities which embrace fluency of thinking (word fluency, ideational fluency and associational fluency), flexibility of thinking (readiness to change direction [54] or to modify information), originality and elaboration (elaborating upon ideas and adding details to fill them out). 
This topic has received considerable attention in music theory. Music theory, in fact, has historically received considerable input from models of the creative process (see also the contribution of Cook in this volume): a great deal of post-war musicology has been concerned with issues of compositional creation, whether in the form of the genesis of individual works, or a composer's creative process as a whole. Traditional research, however, has focussed mainly on the compositional process (Sundin, McPherson \& Folkestad 1998, Van Ernst 1993, Bennett 1976) or on methods for analysing the genesis of particular compositions of individual composers (Beethoven, Strauss, Hindemith, Sessions and Stravinsky, see Sloboda 1985, Cook 1990, Cooper 1990) rather than on the processes at work in musical creativity. This means that music theorists writing on compositional creativity have suffered from ignorance of psychological and related work on creativity so that their work has consequently lacked any kind of adequate theoretical grounding. What is needed, therefore, is a working definition of creativity that has descriptive and explanatory power as well. Johnson-Laird (1988) provides an interesting starting point in his description of the basic characteristics of the creative process: (i) it mostly starts from some given building blocks, (ii) it has no precise goal, only pre-existing constraints or criteria that must be met, and (iii) it yields an outcome that is novel for the individual.

Following these lines of thought, Johnson-Laird distinguishes between three computational architectures for creation. The first is a "neo-Darwinian" architecture, which arbitrarily combines elements in order to generate putative products, and which uses constraints to filter out the products that are not viable; this is a highly inefficient procedure, because most of the products will not be viable. The second is a "neoLamarckian" architecture in which the organism adapts to the environment and can convey these adaptive constraints to its progeny: here a set of constraints is used to generate viable possibilities which are generated under their guidance, with an arbitrary choice being made from amongst them. Since there is only a relatively small number of products which meet the needed criteria, this architecture is highly efficient. The third architecture, finally, is a "multi-stage" design, which uses constraints both to generate ideas and to select the viable ones (Johnson-Laird 1988, p.258). 
The translation of these ideas to the realm of music is challenging, as creative achievements involve both generation and selection. As such we can argue for a multistage approach to musical creativity. The whole construction, however, is computational in the sense that it relies on existing elements which are available for judgement and for assembling into novel arrangements, and as such it fits in with existing theories of creativity which take as their starting point a set of discrete elements on which to do the computations: conceiving of music in terms of pitches, chords, scales, arithmetically related durations and other recognized groupings calls forth a formal-symbolic approach to music cognition, allowing the music user to process the music in an [55] autonomous way without perceptual bonding. It is also possible, however, to conceive of music in terms of a continuous renewal of the elements that are part of the music user's knowledge base. This is a position which is related to the constructivistic approach to music cognition and which stresses epistemic transactions with the sonic world.

Two questions are important here: what are the elements, and what are the computations we can carry out on them? In order to solve this problem we can rely on the control system and conceive of music users as learning devices building up semantic linkages with the sonic world. They behave as adaptive systems interacting with their surroundings through perception and action, and determining the categories of perception and action that are available to the system: unlike animals, which are constrained in their perceptual distinctions and actions on the world, a human organism can change its "semantic linkages" with the world (Cariani 2001a). There is, of course, a lot of freedom here, but it is possible to reduce the virtual infinity of elements by perceptual and cognitive constraints. There is, in fact, a tension between things which can be denoted in an act of mental pointing and the mental operations which can be performed on them, and it is the latter (rather than the former) which are decisive in the delimitation of the elements (Reybrouck 1999, 2003). Through the processes of selecting and delimiting, it is possible to improve our grip on the observables through the related processes of discrimination and generalisation. And the same holds true for such basic operations as assembling, ordering, and bringing into relation, which are closely related to the mental operations of classifying, seriation, bringing into correspondence and combining (Piaget 1967, Reybrouck 2004a). As such we measure and control the environment rather than merely representing it. 
As to the elements, we might draw a distinction between "combinatorial" and "creative emergence", with the former referring to the novelty that results from fresh combinations of pre-existing elements (see Sagi \& Vitanyi 1988, Merker 2002), and the latter refering to the "de novo" creation of new kinds of elements (Cariani 1997). But I consider this distinction to be gradual rather than qualitative. Creativity in music is combinatorial in a radical sense, but it is creative only to the extent that the elements and their combinations yield a product that can be perceived as something new. As such there is always the possibility of making "new distinctions" and this is perhaps the hallmark of the creative musician, be it at the level of listening, performing or composing. Listening again and again to the same music, for example, can exhaust the possibilities of knowledge acquisition: in such cases, the music user no longer behaves as an adaptive and informationally open system, but as a closed system that has cut off its interactions with the sonic world. Rather than looking for new distinctions and observables, the system relies on recognition-in cognitive terms a highly economical strategy, since it is much easier to deal with symbolic representations which are already installed in the music user's mind than to build new representations in the act of dealing with the music.

[56] This marks the basic distinction between "assimilation" and "accommodation": the former allows the music user to perform mental operations in the absence of sensory input, while the latter involves a continuous interaction with the sensory material, relying on the rate-dependent processes involved in perceiving and acting. Once the music user has accommodated, however, it is possible to deal with the music at an internalised level as well, and this is basically the advantage of symbolic modelling and computation: it allows the music user to process music out-of-time, with the possibility of rate-independent storage and retrieval operations.

\section{Conclusions and perspectives}

In this paper I have argued for a definition of musical creativity as "adaptive behaviour" at the three distinctive levels of the epistemic control system (input, output and central 
processing). This means that we must consider the process of coping with the sonic world as one of "measuring" and "controlling" the sounding environment rather than merely "representing" it; in addition, it means that we can modify the "cognitive" and "computational part" as well. This approach emphasizes the flexibility of our cognitive apparatus and allows us to deal with music in terms of knowledge acquisition, thinking and problem solving in general.

The three levels of the control system are moreover complementary components of creativity: they allow us to think of creative music users in terms of "adaptive semantics" and "syntactics" operating at the level of the epistemic control system. On the "input side", we can conceive of musical creativity in cognitive terms, stressing the role of knowledge acquisition and the selection of new observables. This locates creativity at the input as well as the output side, a claim the significance of which cannot be overstated: creativity in music is always related to exploratory listening, be it at a manifest (presentational immediacy) or virtual level (ideational mediation). The "computational part", in turn, allows the music user to perform internal computations and symbolic modelling. The "output side", finally, is more problematic, as many of the actions on the sonic world must be considered as internalised actions (mental operations), which belong to the computational part rather than to the output side. It is legitimate therefore to conceive of musical creativity as in part a "short-circuiting" or "bypassing" of the effector part of the epistemic control system.

\section{References}

Aigrain, Ph. (1999). New Applications of Content Processing of Music. Journal of New Music Research, 28, 4, 271-280.

Bel, B. \& Vecchione, B. (1993). Computational Musicology. Computers and the Humanities, 27, 1.

Bennett, S. (1976). The process of music creation: interviews with eigth composers. Journal of Research in Music Education, 24, 1, pp. 3-13.

Berthoz, A. (1996). The role of inhibition in the hierarchical gating of executed and imagined movements. Cognitive Brain Research, 3, 101-113. 
Berthoz, A. (1997). Le sens du mouvement. Paris: Odile Jacob.

Cariani, P. (1989). On the design of devices with emergent semantic functions. State University of New York: Unpublished Doctoral Dissertation.

Cariani, P. (1991). Some epistemological implications of devices which construct their own sensors and effectors. In Varela, F., \& Bourgine, P. (Eds.), Towards a Practice of Autonomous Systems, Proceedings of the First European Workshop on Artificial Life (pp. 484-493). Cambridge, MA: MIT Press.

Cariani, P. (1997). Emergence of new signal-primitives in neural systems, Intellectica, $2,25,95-143$.

Cariani, P. (1998a). Epistemic Autonomy through Adaptive Sensing. Proceedings of the 1998 IEEE ISIC/CIRA/ISAS Joint Conference Galtherburg, MD - September 14-17, 1998.

Cariani, P. (1998b). Life's journey through the semiosphere. Semiotica, 120-3/4, 243257.

Cariani, P. (2001a). Cybernetic systems and the semiotics of translation. In S. Petrilli (Ed.). Lo Stesso Altro. Athanor: Filosofia, Arte, Letteratura, Semiotica, Filosofia (pp. 256 - 273). Roma: Meltemi, XII, 4.

Cariani, P. (2001b). Symbols and dynamics in the brain. BioSystems, 60, 1-3, pp. 59-83. Special issue on "Physics and evolution of symbols and codes".

Cook, N. (1990). Music, imagination, and culture. Oxford: Clarendon Press.

Cooper, B. (1990). Beethoven and the Creative Process. New York: Oxford University Press.

Daniélou, A. (1967). Sémantique musicale. Essai de psychophysiologie auditive. Paris: Hermann.

Deliège, C. (2001). Le temps affronté: les années post-weberniennes. In Deliège, I., \& Paddison, M. (Eds.). Musique contemporaine. Perspectives théoriques et philosophiques (pp. 191-216). Sprimont: Mardaga.

Dewey, J. (1933). How we think. Boston: Heath.

Dewey, J. (1958). Art as Experience. New York: Capricorn Books. (Original work published 1934)

Dufourt, H. (2001). Les principes de la musique. In Deliège, I., \& Paddison, M. Eds.). Musique contemporaine. Perspectives théoriques et philosophiques (pp. 13-83). Sprimont: Mardaga. 
Emmeche, C. (2001). Does a robot have an Umwelt? Reflections on the qualitative biosemiotics of Jakob von Uexküll, Semiotica, 134 (1/4), 653-693.

Fleagle, J. (1999). Primate Adaptation and Evolution. San Diego: Academic Press.

Forte, A. (1973). The Structure of Atonal Music. New Haven: Yale University Press.

Gardner, H. (1991). The unschooled mind: How children think and how schools should teach. New York: Basic Books.

Guilford, J.P. (1967). The Nature of Human Intelligence. New York - Toronto - London Sydney: Mc Graw Hill.

Guilford, J.P. (1979). Cognitive Psychology with a Frame of Reference. San Diego: Edits Publishers.

Hargreaves, D. (1986). The Developmental Psychology of Music. Cambridge - London New York - New Rochelle - Melbourne - Sydney: Cambridge University Press.

Imberty, M. (1996). Linguistic and musical development in preschool and school-age children. In Deliège, I., \& Sloboda, J. (Eds.). Musical beginnings. Origins and Development of Musical Competence (pp. 191-213). Oxford - New York - Tokyo: Oxford University Press.

Johnson, M. (1987). The Body in the Mind. The Bodily Basis of Meaning, Imagination, and Reason. Chicago and London: The University of Chicago Press.

Johnson-Laird, P. (1988). The computer and the mind. An introduction to cognitive science. London: Fontana Press.

Klaus, G. (1972). Kybernetik und Erkenntnistheorie. Berlin: Deutscher Verlag der Wissenschaften.

Lakoff, G. (1987). Women, Fire, and Dangerous Things: What categories reveal About the Mind. Chicago: University of Chicago Press.

Lerdahl, F. (1988). Cognitive constraints on compositional systems. In Sloboda, J. (Ed.), Generative Processes in Music. (pp. 231-259). Oxford: Clarendon Press.

Merker, B. (2002). Music: the missing Humboldt system, Musicae Scientiae, V1, 1, pp. 321.

Meystel, A. (1998). Multiresolutional Umwelt: Towards a semiotics of neurocontrol, Semiotica, 120, 3/4, 343-380.

Paillard, J. (1990). Réactif et Prédictif: deux modes de gestion de la motricité. In Nougier, V., \& Bianqui, J.-P. (Eds.), Pratiques sportives et modélisation du geste (pp. 13-56). Grenoble: Université Joseph-Fourier. 
Paillard, J. (1994). L'intégration sensori-motrice et idéo-motrice. In Richelle, M., Requin, J., \& Robert, M., Traité de psychologie expérimentale. 1 (pp. 925-96). Paris: Presses Universitaires de France.

Papousek, H. (1996). Musicality in infancy research: biological and cultural origins of early musicality. In Deliège, I., \& Sloboda, J. (Eds.). Musical beginnings. Origins and Development of Musical Competence (pp. 37-55). Oxford - New York - Tokyo: Oxford University Press.

Pattee, H. (1995). Artificial life needs a real epistemology. In Moran, F., Moreno, A., Merelo, J., \& Chacon, P. (Eds.). Advances in Artificial Life. Lecture notes in artificial intelligence. Berlin: Springer.

Piaget, J. (1967). Biologie et connaissance. Essai sur les relations entre les régulations organiques et les processus cognitifs. Paris: Gallimard.

Reybrouck, M. (1999). The musical sign between sound and meaning. In I. Zannos (Ed.). Music and Signs, Semiotic and Cognitive Studies in Music (pp.39-58). Bratislava: ASCO Art \& Science.

Reybrouck, M. (2001a). Biological roots of musical epistemology: Functional Cycles, Umwelt, and enactive listening. Semiotica, 134, 1-4, 599-633.

Reybrouck, M. (2001b). Musical Imagery between Sensory Processing and Ideomotor Simulation. In Godøy, R.I., \& Jörgensen, H. (Eds.). Musical Imagery (pp. 117-136). Lisse: Swets \& Zeitlinger.

Reybrouck, M. (2003). Musical semantics between epistemological assumptions and operational claims. In E.Tarasti (Ed.). Musical Semiotics Revisited. Acta Semiotica Fennica XV (pp. 272-287). Imatra: International Semiotics Institute.

Reybrouck, M. (2004a). A biosemiotic approach to music cognition: event perception between auditory listening and cognitive economy. Axiomathes. (Forthcoming) Reybrouck, M. (2004b). Music cognition, semiotics and the experience of time: ontosemantical and epistemological claims. Journal of New Music Research. (Forthcoming)

Rossman, J. (1931). The psychology of the inventor. Washington, D.C.: Inventor Publishing Co.

Sagi, M., \& Vitanyi, I. (1988). Experimental research into musical generative ability. In Sloboda, J. (Ed.). Generative Processes in Music. The Psychology of Performance, Improvization, and Composition (pp. 179-194). Oxford: Clarendon Press. 
Sloboda, J. (1985). The Musical Mind. The cognitive psychology of music, Oxford: Clarendon Press.

Sundin, B., McPherson, G., \& Folkestad, G. (1998). Children Composing. Sweden: Lund University.

Van Ernst, B. (1993). A study of the learning and teaching processes of non-naïve music students engaged in composition. Research Studies in Music Education, 1, 22-39.

von Glasersfeld, E. (1995). Radical Constructivism: A Way of Knowing and Learning. London - Washington: The Falmer Press.

von Uexküll, J. (1957). A Stroll Through the Worlds of Animals and Men. A Picture Book of Invisible Worlds. In C. Schiller (Ed.). Instinctive Behavior. The Development of a Modern Concept (pp. 5-80). New York: International Universities Press.

(Original work published 1934)

Wallas, G. (1945). The art of thought. London: Watts. (Original work published 1926)

Webster, P.R. (1990). Creativity as Creative Thinking. Music Educators Journal, 76, 9, 22 28.

Webster, P.R. (1992). Research on creative thinking in music: the assessment literature. In R. Colwell (Ed.). Handbook of Research on Music Teaching and Learning. New York: Schirmer Books.

Ziemke, T., \& Sharkey, N. (2001). A stroll through the world of robots and animals: Applying Jakob von Uexküll's theory of meaning to adaptive robots and artificial life, Semiotica, 134 (1-4), 701-746. 